\title{
CONSTRUCTING AND REPRESENTING: A NEW PROJECT FOR 3D SURVEYING OF YAZILIKAYA - HATTUŠA
}

\author{
L. Repola ${ }^{\text {a }}$ M. Marazzia ${ }^{\text {a }}$ S. Tilia ${ }^{a}$ \\ ${ }^{a}$ Suor Orsola Benincasa University, via Suor Orsola 10, 80135, Napoli - repolaleopoldo@gmail.com
}

Commission VI, WG VI/4

KEY WORDS: Survey, Representation, Technology, Archeology, Exhibit Design, Topography, Cultural Heritage

\begin{abstract}
:
Within the cooperation project between the University Suor Orsola Benincasa of Naples and the archaeological mission in Hattuša of the German Archaeological Institute of Istanbul, directed by Andreas Schachner, in agreement with the Turkish Ministry of Culture and Tourism, the workgroup of the University of Naples, has carried out, in September 2015, a first survey campaign of the whole rocky site of Yazılikaya.

The experimentation has been finalized at constructing a global 3D territorial and monumental model of the site, capable that is, through the application of differing scanning procedures, according to the different components (topography, rocky complex, the cultural spaces therein, complex of sculptural reliefs, inscriptions accompanying the divine representations), of virtually reproducing in detail, for safegaurd, exhibition and study purposes (in particular from an epigraphical and historic-artistic point of view) all the aspects characterizing the artefact and not completely visible to the naked eye today.
\end{abstract}

\section{INTRODUCTION}

\subsection{The archaeological site of Hattuša}

The archaeological site of Hattuša, added to the UNESCO World Heritage list in 1986, is the ancient capital of the Hittite Empire, one of the most important "territorial states" of the Near East in the II millennium B.C. It is notable for its urban organization, the types of constructions that have been preserved (temples, royal residences, fortifications), the rich sculptural ornaments like at the Lions', the Sphinxes' and the Royal Gates (Schachner, 2011), or the ensemble of the rocky sanctuary at Yazılıkaya, a religious monumental complex a few kilometres from the Capital.

Within the cooperation project between the University Suor Orsola Benincasa of Naples and the Archaeological Mission in Hattuša of the German Archaeological Institute of Istanbul, directed by Andreas Schachner, in agreement with the Turkish Ministry of Culture and Tourism, the workgroup of the University of Naples, has carried out, in September 2015, a first survey campaign of the whole rocky site of Yaz1lıkaya.

\subsection{The sculptural reliefs of Yazlıkaya}

The rocky complex of Yazllikaya represents one among the most famous and imposing monuments of the whole ancient Near-East. The architectural complex, probably conceived by one of the most significant dynasts of Hittite history, Hattusili III (second half of the XIII cent. B.C.E.), key player, among others in the peace treaty between the Kingdom of Hatti and Pharaoh Ramses II, was effectively brought to completion by his son Tuthalija.

It consists of a "labyrinth" of large limestone slabs that emerge along a slope placed at around 3 kilometres north of the capital Hattuša.

Already a worshipping place in ancient-Hittite times (XVI Century B.C.), it was chosen by Hattusili (III) and by his son Tuthalija (IV) as a "scenery" where to visibly celebrate the kingdom's complex pantheon. The morphology of this natural rocky environment was well adaptable, in fact, with its spaces surrounded by steep walls and narrow passages, capable of connecting them together, to the function of a real sanctuary immersed in an extremely evocative natural setting [Figure 1].

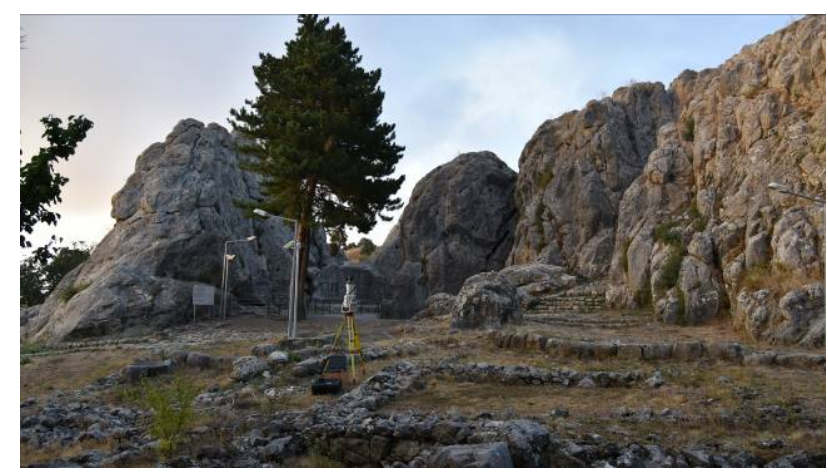

Figure 1. The rocky complex of Yazılıkaya

On the south-west front of the rocky complex, from which the larger internal area defined as "Chamber A" was accessed, a number of buildings were constructed during the span of time, having the function of a monumental entrance to the sacred complex. Their most recent arrangement must have been carried out under the reign of Tuthalija in connection with the program for the sculptural decoration put into place both in the above mentioned "Chamber A" and both in the adjoining "Chamber B".

Two divine series in relief, one feminine, the other masculine, were represented while proceeding along the longer wall sides of Chamber A, as to accompany on left and right-hand sides whom had exited the courtyard of the building in front, accessing the former through a purpose-built entrance. This space had its focal point on the shorter back wall where the two processions met each other in the persons of respectively of the two most important female and male divinities of the reign's pantheon: the goddess Hebat and the "stormgod" Teshub/Tarhunza.

Some of the main divinities, represented as in a procession, have in front of their figure, at the height of their face, an Hittite 
hieroglyph inscription, written from top to bottom, which indicates (often through complex scripture artifices) their name. Chamber B, whose access, originally equipped with its own independent propylon placed further south and later incorporated in the main building, was probably dedicated to the function of mausoleum for king Tuthalija himself. In it, a series of other sculptures, representing primordial and chthonic divinities, are accompanied by two relief representations of the king: the first one depicts him in large size in the classic "embrace" with his tutelary deity, the god Sarruma. Both are accompanied by their denomination in hieroglyphic script: the one of the god, like the other divinities represented throughout Chamber A, is placed in front of his face, a sign apparently "sustained" by his forward extended arm. The king's, which is placed high on the right, is expressed with the classic royal "aedicula" of the period, where the name of the dynast is enclosed within a winged sun on top (with the appellative meaning "my sun") and on the sides, with an heraldically repeated double titling, the titles of Labarna, (from the name of the legendary founder of the royal dynasty of Hattuša) and that of "great king". The second representation of King Tuthalija consists de facto, of the sole royal aedicula.

Such second Chamber, on which walls 3 niches have been obtained, probably for the deposition of ritual objects or maybe for the sheltering of a funerary deposition, should in origin have contained also a statue of the king to which the religious space was dedicated and whose base could be identified with that found among the reused spoils found in the village of Yekbas, a few kilometres away.

Other relief sculptures, in addition to the ones described above, adorn the spaces offered by the walls. The more recent entrance to Chamber B, a narrow passage immediately to the right of the space in front of Chamber A, appears "protected" by two winged though anthropomorphic demonic figures, placed respectively to the right and the left of the entrance to this narrow passage. To the right of the entrance to Chamber A, a scene of a banquet is visible characterized by two sitting deities, accompanied each by its proper identification in hieroglyphic script. Monumental instead is the representation of King Tuthalija inside Chamber A, on the right hand side, right before the line of proceeding female deities.

To each relief, whether accompanied by a hieroglyphic inscription or not, a progressive number has been assigned by scholars: for Chamber A the numbers go from 1 to 63 for what concerns the lines of proceeding deities, number 64 has been assigned to the monumental representation of Tuthalija. The banquet scene and the two demons are numbered from 65 to 68 , while to the sculptures in Chamber B the numbers from 69 through 83 have been assigned.

Quite probably, other sculptural decorations must have been located within the sacred complex. They were presumably located on separate slabs of stone and placed as closures in front of the natural crevices, which characterized the rocky walls of the two chambers. As an example, in the case of Chamber A, the female procession must have contained slab/block plugs in at least in two points. Moreover, in fact, a limestone block, again found in the nearby village of Yekbas, representing a proceeding female divinity preserved in its entirety and behind it a hieroglyphic script mentioning a second one, now lost, must have certainly been located originally as a closure of one of these two spaces.

\section{ROCKY ARCHITECTURES AND DIGITAL SIGNS}

\subsection{The surveyed areas}

During the month of September 2014, an initial survey campaign was carried out on the site of Hattuša. The chosen area was that between the s.c. Südburg and Nişantepe, in the Oberstadt. This location, with the two hierogliphic monumental inscriptions of Nișantaș and Kammer 2 in the Südburg, offered in fact, both the possibility of performing a topographical survey capable of including monumental complexes of particular interest and to experiment with specific scanning procedures dedicated to the study of hieroglyphic epigraphic evidences placed on architectural elements and a cliff wall respectively (Schachner, 2016). Furthermore, the particularly eroded nature of the cliff wall of Nișantaș, offered the possibility of testing to what degree $3 \mathrm{D}$ models, following adequate processing, could effectively highlight traces of signs not visible to the naked eye (Repola, 2016).

The field activities continued in October 2015 in the area of the rocky complex of Yazılıkaya. In this case the experimentation has been finalized at constructing a global 3D territorial and monumental model of the site, capable that is, through the application of differing scanning procedures, according to the different components (topography, rocky complex, the cultural spaces therein, complex of sculptural reliefs, inscription accompanying the divine representations), of virtually reproducing in detail, for protection, exhibition and study purposes (in particular from an epigraphical and historic-artistic point of view) all the aspects characterizing the artefact and not completely visible to the naked eye today. In fact due to the direct exposure of the decorated walls to atmospheric phenomena, many parts of the reliefs and relative inscriptions appear today as particularly degraded, to such extent that in some cases their reading is near to impossible. In particular, the hieroglyphic inscriptions, which accompany the divine representations are of difficult identification and the signs are visible only in particular lighting conditions.

In order to create such a "complex model", a number of differentiated scanning procedures were devised in order to adequately represent the peculiarities of the single aspects to be surveyed. The composition of the global model was thus carried out through new interpolation processes of the generated single and partial models.

\subsection{Instruments and procedures}

Attention was concentrated essentially on two activities:

1. That of a mixed survey: both with innovative hardware (commercial or not), and with scanners already on the market, but adequately modified;

2. That of the creation of new scanning protocols, adaptable to the diverse archaeological realities (monumental, epigraphical, artistic) and to the different material characteristics of the artefacts, in particular with respect to the surfaces (degradation phenomena and resulting modification of material peculiarities). The surveying activities, data verification, interpolation and production of models to support the analysis of the hieroglyphics, were realized in an integrated manner. The territorial survey phases, carried out through laser scanner, total station and photogrammetric systems, were correlated to the $3 \mathrm{D}$ structured light scanner digitizing procedures of the reliefs in order to verify the correspondence between the models, possible areas of shadow, the levels of mutual definition of homologous parts, typological schemes of representation referred to various 
figures and signs engraved into the rock. The same major phases in the field were planned at different times of the day in order to make the most of the light and the darkness of the sites in relation to the type of instruments and systems used. All data was verified within a single virtual space, referenced by topographic survey, into which territorial architectural models and products with TOF laser scanner (based on the coordinates of the markers acquired by the total station), and detail of the reliefs acquired with image-based systems and structured light were imported (aligned both through topographic markers for detail survey and through formal homology).

The instruments used during the 2014-2015 campaign consisted of:

Time Of Flight (TOF) type Laser Scanner (in the specific case a Riegl LMSi 420, modified for a better performance in topographical surveying) [Figure 2]. In the case of the 3D scanning project in Hattuša, the use of this type of scanner has been directed mainly to the generation of territorial models to be interpolated with models of specific monuments or particular elements (inscriptions, architectural elements etc.). In parallel to the static types of survey, a system (developed within the NOP SINAPSIS project) of dynamic surveying (of the Mobile Laser Scanning - MLS type) mounted on a moving vehicle was tested.

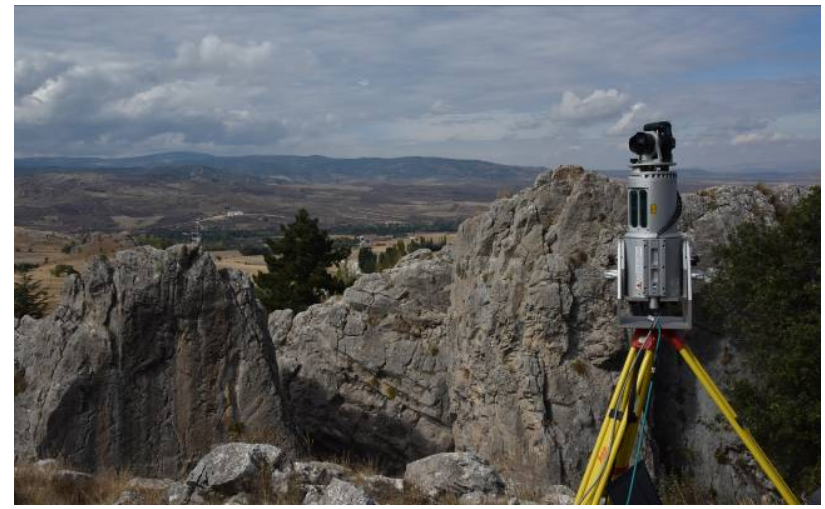

Figure 2. TOF-laser scanner activity in the Yazılıkaya

Structured Light type Scanner (in the specific case an ARTEC model was used) [Figure 3]. Thanks to the extremely high acquisition speed, up to 500,000 points per second, this type of scanner adds such speed to a very high accuracy (up to $0.5 \mathrm{~mm}$ ) and resolution (up to $0.1 \mathrm{~mm}$ ). Furthermore, it enables the acquisition of the 3D shape of an object together with its colours. The scanner is capable of acquiring a brilliant colour spectrum (up to $24 \mathrm{bpp}$ ) thus enabling the attainment of a highresolution model complete with texturing. Taking into account its high portability, low weight and manageability, it was deemed particularly apt for the scanning of monumental epigraphical or artistic elements. In order to obtain a more effective acquisition procedure of the articulate inscribed surfaces belonging to Nişantaş, to the Kammer 2 of the Südburg and the rock reliefs of Yazilikaya, a procedure was devised aimed at the attainment of a high level of continuity of the points even though their number was reduced. The procedure concerning the use of the instrument was planned on location based on the dominating geometries of the signs and shape of the area to be surveyed. In fact, a number of reference geometries were defined by juxtaposing a number of markers on the rock, roughly in a square grid pattern in order to avoid more passages on the same areas. Successively, as a mean of progressive verification of acquired data through a number of test acquisitions, a correct velocity of movement was established together with the maximum area to be acquired. Furthermore, in order to obtain a coherent point cloud in each portion of the carved/inscribed surface, a vertical ondulatory course was followed with the instrument, combined with a continuous horizontal movement (for the most extensive areas) and vertical (for the smaller ones). In this way, though guaranteeing a reduced redundancy of points, it was possible to obtain a high coherency of points close to the differences in height belonging to the inscribed signs.

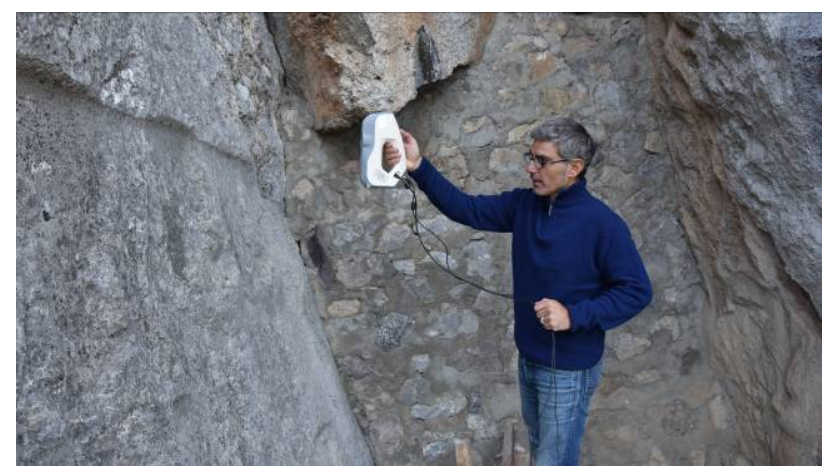

Figure 3. Acquisition procedures with the Artec Eva

Scubalibre Stereoscopic Scanner. Within the NOP SINAPSIS project, a tri-dimensional underwater and terrestrial scanning system was developed, functioning through the processing of images, aimed at the surveying of submerged and coastal archaeological sites, which could be integrated with the standard systems for the geomorphological surveying of coasts. The project involved the creation of a hardware system, composed of a supporting steel structure with two GoPro Hero Black Edition cameras arranged to guarantee the parallelism between the main axes [Figure 4], and of a related software capable of producing point clouds and to certain extent process such data. The use of this scanner at Hattuša has been aimed mostly towards the survey of the inscribed or relief carved surfaces, in order to obtain models dedicated to analysing the volumetric ratios. The transportability and the lightness of the instrument made it ideal for its use in situations where acquisitions was difficult and of specific elements.

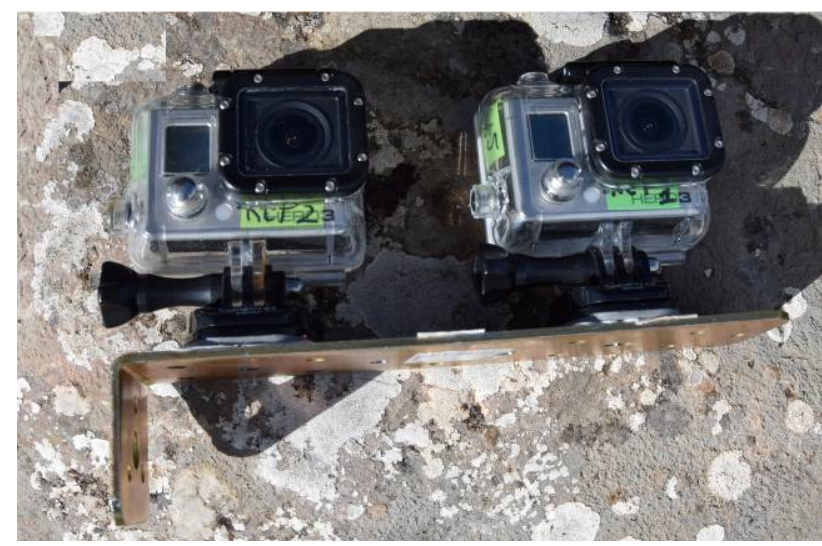

Figure 4. Scubalibre Hardware - prototype

PhotoScan procedures [Figure 5]. The survey procedure with PhotoScan was concentrated on the acquisition (in extremely high definition) of the natural cliff wall comprising the Nișantaș inscription and the (inscribed) sculptures of Yazilıkaya, in order 
to generate a 3D base model and a 2D orthophoto onto which implement various interpolation and presentation procedures (augmented reality, immersive environments etc.). During the topographical campaign of 2015 of the rocky area surrounding the "massif" of Yazllikaya, a new form of interpolation has been experimented between georeferenced models generated from laser scannings and the textures obtained from the models generated by the PhotoScan procedure.

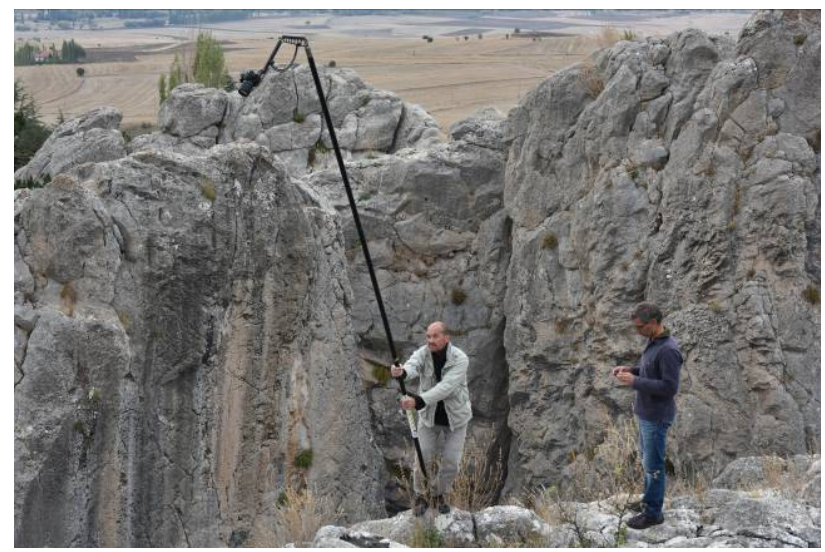

Figure 5. Phases of the PhotoScan procedures

Structured Light Scanner [Figure 6]. The use of the structured light scanner during the campaigns has been used exclusively for the execution of a series of experiments on the inscribed natural rock cliff of Nișantaș and the (carved) sculptures of Yazılıkaya, mainly aimed at the acquisition of the outlines (more or less in relief) of the hieroglyph signs present on the surface. In this field, a series of specific scripts in the development phase of the model, were also tested.

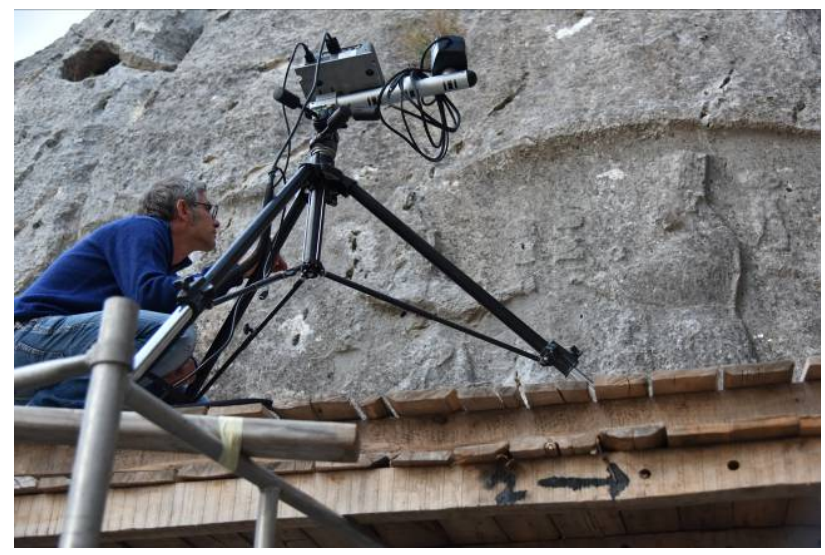

Figure 6. Structured Light acquisition procedure

On the basis of a number of measurements to determine control points with which to connect both the topographic scans and specific ones concerning particular monuments or parts of them and in accordance with the nature of each artefact, scanning operations were carried out, using diverse but simultaneous procedures at different times of the day, to utilize the different lighting conditions.

\subsection{Topographical survey}

The main goal of the topographic surveying campaign carried out for the site of Yazillkaya was the inclusion of the detailed map of the structures placed to the south of Chambers A and B inside the general map of Hattuša. In this respect, it was decided to proceed by placing the survey within the local reference system used for this general map thus excluding, in first instance, a true georeferencing. In order to obtain this objective, three datum points were chosen as reference, all of them placed on the high sector of the city of Hattuša: the Büyükkaya hill. The reason for this choice was that they were directly observable from Yazılıkaya and thus measurable from a single station placed near the latter site (on the western edge of its parking lot). The datum points, materialized on the ground as metal nails, had denominations: 152, 153 and 155 and were clearly indicated on the aforementioned general map together with other datum points that were not considered due to their more difficult observability. The three datum points were measured through a Leica TCR405 total station; this procedure enabled the placement of a number of stations throughout the site of Yazıllkaya, in a useful manner for the subsequent operations to be carried out here and, above all, tied to the reference system described above.

The operations that followed were mainly dedicated to supporting the TOF laser scanning survey of the entire site, in particular regarding the topographic rendition of the natural rock outcrops that characterize it. In order to combine the various scanned point clouds and to provide them with coordinate referencing and dimensioning, a number of special reflective markers were placed, with an appropriate distribution, throughout the area under survey and then measured with the total station. These enabled the union of the various point clouds where the same marker detected in two or more scans would act as a connection point in a process also known as point cloud "registration" which was carried out in postprocessing in the Riscan software provided with the TOF laser scanner.

This operation is a well-established and quite standard procedure for laser scanners dedicated to topographic survey. These types of laser scanners can also provide the "colouring" of the point clouds and the processed meshed models thanks to internal or external cameras that work in unison with $3 \mathrm{D}$ data acquisition (coaxially or with a certain amount of parallax respectively). The limitation of this characteristic resides in the difficulties of providing a consistent colouring of all points in the cloud especially where the angle of incidence of the outgoing laser ray and hence the camera's line of sight in respect to the surface to be acquired is very acute. Since one of the main objectives of our task was to survey all surfaces of the site, recording also their colouring in a consistent and, above all, highly detailed manner, the images provided by the scanning device would not be sufficient. It was thus decided to combine the laser scanner acquired models with models and textures obtained through photogrammetric means.

This particular procedure was applied to the higher grounds present just east of the site's Chamber B where the colouration of the point clouds through laser scanner (on board camera) had proved very difficult due to the extremely jagged nature of the rock outcrops present here. The software employed was PhotoScan by Agisoft, a very versatile and practical (though not rigorous) tool for $3 \mathrm{D}$ model acquisition through photographs. Images were acquired of the whole area both from a zenithal point of view, through a camera mounted on a $5 \mathrm{~m}$ high pole and both from a lower "eyesight" and more angled point of view in order to cover the more vertical surfaces otherwise not fully 
visible directly from above. As in laser scanning, photogrammetry also requires control points for a proper restitution (image pair matching) of dimensionally correct and georeferenced 3D surfaces, it was decided to use the same points that had been surveyed for laser scan point cloud registration which were well visible in the acquired images. A total of 324 images were selected among the many acquired for the restitution in addition to 15 control points.

The 3D models thus produced were instrumental for the extraction of well detailed and chromatically consistent "textures" to be used on all 3D model surfaces, whether laser scan or photogrammetrically derived [Figure 7].

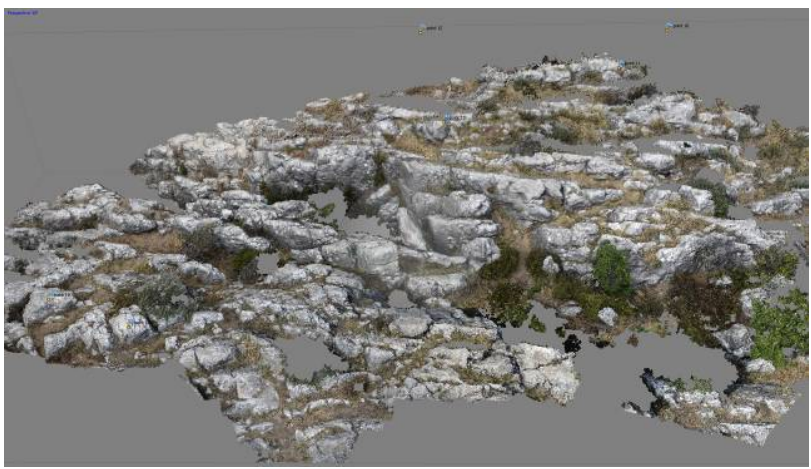

Figure 7. Point Cloud of the rocks produced by PhotoScan

\subsection{Laboratory experimentation and processing}

Already during the field scanning activities (and then successively at the University labs in Naples) it was possible to generate the first models and experiment with a series of interpolation procedures between models generated from the same or different scanning techniques.

The first tests of interpolation both between models generated by the same means of scan acquisition and between models generated through heterogeneous techniques, have been carried out for the Chamber A and the Chamber B. The early stages of data management consisted in the alignment of point clouds produced by a Riegl TOF scanner, by importing the topographic coordinates of the markers detected by the total station, within the local reference system. Then the data relative to the various acquisition positions were cleaned of vegetation and filtered to eliminate the effects of noise. The high-resolution point clouds were joined into a single model representing the entire archaeological area [Figure 8], which was successively divided into parts depending on the identification of the various acquired surfaces (i.e. soil, rocks, and "architectural structures").

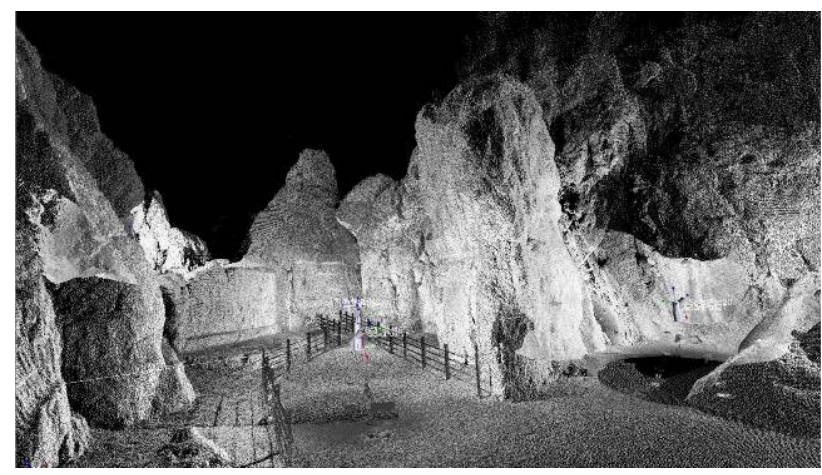

The three parts were handled ensuring different levels of definition, specifically, the point cloud relative to the ground, namely the areas between the rocky outcrops and archaeological area limits, have been greatly discretized and rendered by means of a reduced number of polygons, partly because of the dense vegetation on site; data referring to the limestone outcrops were divided into rock surfaces and extended planes delimiting the Chambers, also called "architectural structures", and processed while maintaining a high number of polygons. In order to better handle the large amount of data, the general model of the monumental complex was divided into parts according to the geometries of the rock blocks, and in particular the walls of the Chambers and the decorated surfaces. In order to allow a progressive verification of all the information produced with the different tools, the clouds generated by means of image-based and structured light scanning systems, referred to the decorated parts, were processed simultaneously to the clouds relative to rocky planes on which they laid. In this way, it was possible to optimize the geometric quality of the models produced by the TOF scanner in order to ensure reduced levels of approximation in alignment procedures, for homologous points, of the detailed models.

Particular importance was given to the area placed above Chamber B, both during the surveying phase and during data processing, due to the strong inconsistency of rocky outcrops, characterized by a high number of cracks and splits. In this area three acquisition systems were integrated: total station, time of flight laser scanner, modelling from images, through the positioning on the field of three types of markers: 2.5 by 2.5 centimetres, high contrast markers (in support of the referencing and orthophotogrammetric rectification phases of photos), cylindrical 5 and 10 centimetres and 5 centimetres diameter round discs of (for the automatic alignment of the various scan positions by means of the RiscanPro software). Starting from the referencing of the three types of markers in a single reference system, they were automatically aligned with the general models produced with the Riegl scanner, which, given its distance measuring range of up to 800 meters, was able to return the entire orographic context in addition to the summit parts of the rocky walls (hardly detectable inside the chambers due to their reduced width), and the detailed models generated from images, that due to the handling of the system, consisting of a camera mounted on a 5 metre high pole, allowed an accurate survey of the complex rocky surfaces up to the edge of Chamber B. [Figure 9]

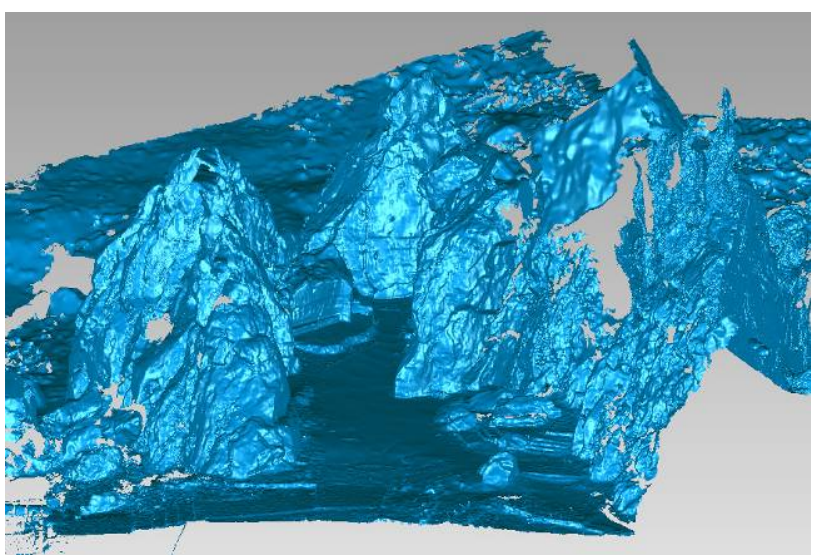

Figure 9. Polygon model of the rock

Figure 8. Point cloud of the Chamber A 
Given the complexity of both the architectural-topographical models and those of the relief's detail, it was necessary to plan a strict management process of the models and their visualization through specific software to support the phases of use of the information. In particular, the $3 \mathrm{D}$ digitization campaign was aimed at supporting the initial activities for the possible verification of interventions for the safeguard of the monument, scientific study of the reliefs and hieroglyphics and the "musealization" of the area through new forms of digital communication.

In the first case it was decided to produce polygonal models of the rocks, giving particular importance to the crests and the horizontal summit surfaces of the structures, this in order to detect with accuracy the cutting planes of the slabs and the mutual position of the stone blocks both for recording any displacement and cracking phenomena underway on the surfaces, both to understand the trajectories of running rainwater, the latter responsible for the widespread phenomena of exfoliation of the rocky planes.

The models were managed within the Rhinoceros software in order to produce the necessary CAD files to support any of the safeguard interventions through filling of cracks for restoring the continuity of the rocky (calcareous) planes and covering by means of protective mats or, in particular for the areas above and in proximity of Chamber $\mathrm{B}$, by means of lightweight structures. The latter, starting from the geomorphological models of the area, could be produced through parametric software, such as Grasshopper, in order to avoid anchoring elements and be anyhow resistant thanks to the curvature of the structures. These covering structures, based on the gridshell model, designed as much as possible adherent to the natural surfaces in order to abate visual impact, would guarantee protection from rain of the rocky surfaces next to the chambers, thereby reducing infiltration and icing phenomena of waters, besides the appearance of vegetation and lichens, furthermore they would provide the ability to accommodate secure walkways for the fruition of the monument.

Such structures could be monitored through intelligent nanotechnology systems and based on computer vision in order to gather information, in addition to their state of deformation and operation over time [Colabella, 2015], on the microclimatic conditions at the bottom of the shells (by means of a network of optic fibre measurement points), on security through a diffused anti-intruder system and continuous video monitoring. In reference to the study of the reliefs and hieroglyphics, highdefinition models of the decorated surfaces were produced, with and without texture, in order to ensure differentiated procedures of sign display.

Already during the 2014 survey campaign at Hattuša, it was clear that a fundamental research track would be that of the optimization, through a proprietary system, of the model "visualization" procedures, within a virtual environment, inside which the model (or a portion of it) could be loaded and subjected to diverse and simultaneous forms of manipulation, in order to free it from its original and real position in space.

The first experiments, carried out during the first months of 2015 in the Neapolitan labs, still through the use of commercial software (Studio 3D for the rotation, stretching and multiple static illumination procedures; Geomagic for the rotation and dynamic illumination procedures), have showed how the uploading of adequately processed models of the inscribed wall of Yazılikaya into an environment for virtual visualization where the illumination of models could be manipulated through variable parameters, made it possible to detect traces of strings of signs not observable with a naked eye.
The relative models of every scanning sequence (respectively acquired through: Structured Light, PhotoScan, and Scubalibre) of the entire inscription surface have been ideally subdivided into both "Blocks" (one for each divinity or group of them) in order to operate in visualization with models for easier manipulation [Figure 10].

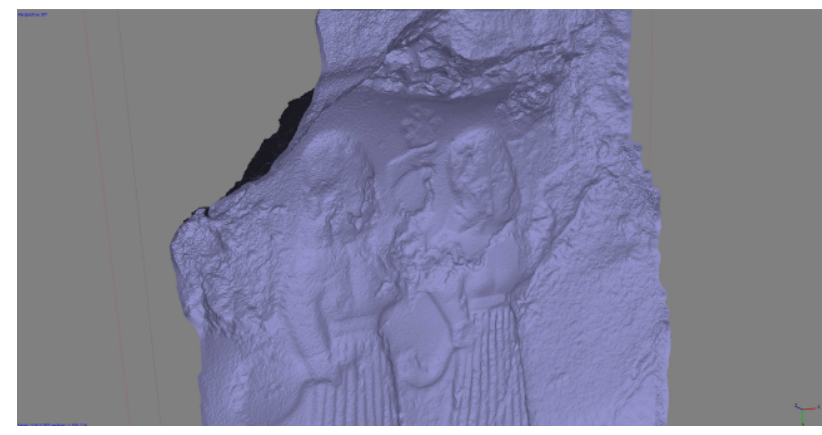

Figure 10. Polygonal Model - Relief of the Chamber A

For every typology of model subdivided in this way, an interactive map was created from which, according to a GIS platform logic, which directly enters into the visualization mode.

The interactive mapping of the models has represented the base for the study of the signs of the inscription. The visualization, illumination, manipulation and stretching procedures performed on each model have in fact enabled the construction a series of images suitable for reading and, consequently, to proceed to the first partial autographies [Figure 11].

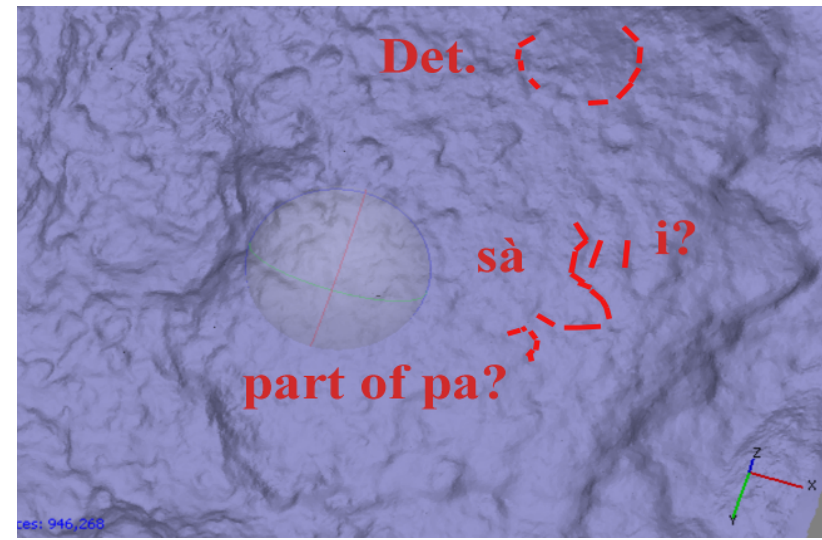

Figure 11. Possible identification of the traces by the model

This work, which is still in progress, consists of a model-bymodel mapping into an interactive general picture.

Every specific image, reproducing a portion of the model after being illuminated, rotated and/or stretched in order to enable an optimal reading of the signs, can be accessed and compared with the preliminary drawings of the autography positioned above the inscription [Figure 12]. 


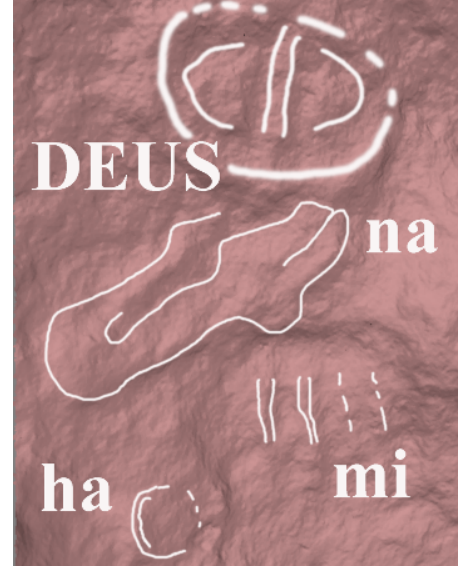

Figure 12. Detail of the hieroglyphic inscription related to the deity 17

The data, subdivided and processed, was also used within the communication strategies of the results of the research.

All acquired and processed data was subsequently used, in the production of a temporary exhibition, in December 2015, at the University of Naples Suor Orsola Benincasa, concerning the Italian archaeological expeditions in Turkey. The 3D models were used for the production of real copies, by means of 3D milling, on which the hieroglyphic signs were mapped dynamically with light projections to enhance their texture and bring them out in high relief. This system of representation has allowed us to join real information, interpretive signs and meanings, with the logical procedures of study and data production by archaeologists. Moreover, 3D models are managed by virtual animations that represent simultaneous views of the monument at different scales of representation. In this way, the natural contexts, of the monument and inscriptions, are able to give a single storytelling of places where beauty, history and legend have led the scientific research, into a deeper understanding of the Hittite civilization.

\section{REPRESENTATION}

\subsection{Exhibition of the signs of matter}

The new instruments and the image based tools for threedimensional scanning guarantee very fast and accurate survey procedures. The research that we are conducting is aimed at analyzing the potential offered by these new forms of digitalization systems in different application fields, to aid in research, cataloguing, preservation and especially the enhancement of Cultural Heritage. Such systems are able to produce $3 \mathrm{D}$ data in augmented and immersive environments, allowing the conceptualization of new kinds of interactive museums, that involve the visitor in the complex dynamics of the perception of contexts and environments (Repola, 2017).

In an age where the digital realm has contaminated fields of what was divided between the real (physical) and the virtual (imagined), it becomes necessary, in fact, to strengthen the analysis of the interactions between perception, quality of data, information processing tools and representation processes.

The digital age has led to fundamental changes in the concepts of time and space, by including them in the complex perception dynamics, extending reality into the vast fields of the virtual world (Deleuze, 1997). The forms, in the digital spaces, have taken on new statutes up to coinciding with the signs, with continuously moving trajectories, in which the points of view cannot be determined for their position in respect with the objects or for their belonging to an instant, but are themselves formed and dispersed in the continuous variation of the virtual places, through cuts in the coexistence of the infinite times. From the extended virtual places the very idea of reality appears to change, the historical time unravels itself, the physical distances travel through the dimensions of the infinitely small and the infinitely large, in which thought and instruments run through the hybrid paths of new forms of critical understanding. Just think of the broader developments obtained through the methods based on machine learning up to the newer frontiers of the levels of representation of deep learning, which increasingly tend to integrate IT processes with the processing states of the mind, with considerable references to the aesthetic perception (Gatys, 2015).

Digital technologies have extended the limits of perception and this has allowed the use of contextual information beyond the first mechanisms of thought determination, generating different levels of critical interpretation, valid for each type of user.

More and more new technologies, usually used by researchers for scientific purposes in the fields of diagnostics and documentation, become tools for communication and promotion of cultural heritage, supporting a continuous process of interconnection of scientific fields that once seemed disjointed. Digital technologies, and the data they produce, are reforming the value of information in relation to their different levels of usability, in the digital age they become relaunching tools for the strengthening of scientific disciplines, placing cultural heritage in the dynamics of widespread, shared, communication. Despite the limitations of available time and resources, the design of the exhibition concerning the Italian archaeological expeditions in Turkey was aimed at investigating, the topics as described heretofore, with particular reference to the potential of the digital realm in the understanding of the symbolic meaning and aesthetic signs through unusual views of the reliefs. The hieroglyphic signs, in particular, by means of 3D modelling, milling techniques using $\mathrm{CNC}$ machines, virtual animations, graphic design, three-dimensional video mapping, have been represented in an integrated manner in order to characterize, along with their linguistic meaning, their strong symbolic value [Figure 13].

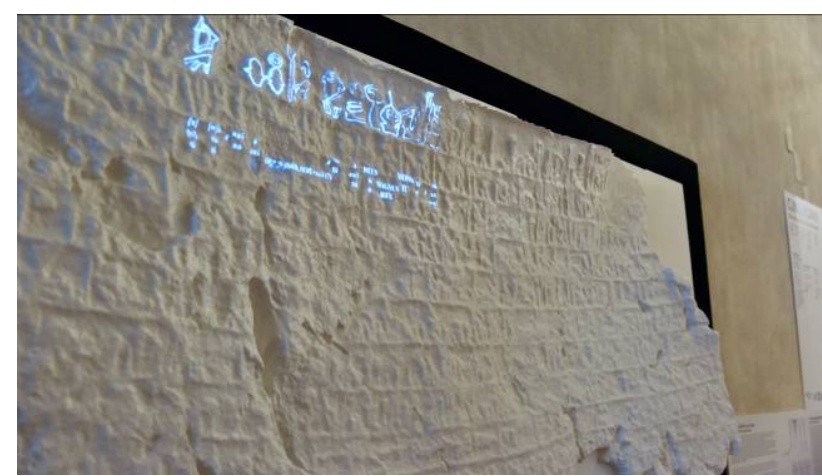

Figure 13. 3D video mapping

Such signs, as universal emblems, depicted the grandeur of the Hittite kingdom, the summary of the scenes and the essential geometry assured its communication effectiveness, their aesthetic value permutated the act of comprehension of a language in the sense of belonging to a people. Such signs, as effigies, in the sequence of narrated events, referred, then as now, to the universality of the story in the act of its determination through the narration. 
Thus the high-resolution 3D models, processed to preserve the material qualities of the rock, have returned the essential and main lines of the hieroglyphic signs, allowing the intimate representation of the variation of the forms, in their becoming writing and figuration.

The virtual medium has thus become the place for the investigation of the sign and instrument for the change of the scales of perception, from the global, from the rock architectures of the chambers, to the infinite proximity of matter, where the wrinkles of the stone curl themselves to become writing. The lights, the milled models, the highresolution digital prints, have defined the last point of the narrative that the earliest forms of writing led to the current lettering of graphic design [Figure 14].

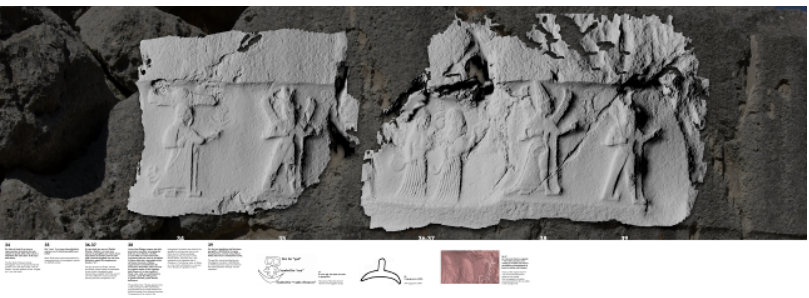

Figure 14. Visualisation system for the exhibition design

\section{CONCLUSIONS}

The research project has enabled the development of an integrated system of a number of three-dimensional survey procedures aimed at the management, in a single virtual space, of spatial patterns and detail of the architectural elements and the archaeological findings of Yazllıkaya. Within such space, the possibility of viewing and managing three-dimensional information at different scales has been verified, characterizing in particular the geometric quality of hieroglyphics to support their interpretation. The data produced was also used for the study of new forms of representation of cultural heritage within exhibition spaces integrated with digital content, made through multilevel narrative schemes, which apply to different types of audience. Procedures for the management of point clouds were created in order to ensure the recording of detailed information in high resolution within extended models of variable definition, according to different display modes. The obtained models were also the basis of the initial aesthetic and formal analysis studies of rock reliefs, for the identification of new forms of their management within relational 3D GIS storage systems.

\section{NOTES}

The paragraphs 1.1 and 1.2 are attributed to Massimiliano Marazzi; the paragraphs 2.1, 2.2, 2.4, 3 and 4 are attributed to Leopoldo Repola; the paragraph 2.3 is attributed to Stefano Tilia.

Acknowledgements of support for the project: For the study of hieroglyphs Natalia Bolatti Guzzo; for the $3 \mathrm{~d}$ modelling and survey Alfredo Cerrato; for the $3 \mathrm{~d}$ modelling Francesco Trimarco.

\section{REFERENCES}

Colabella S., Lancia D., Repola L., Memmolo M., Pone P., 2015. A monitoring system for wooden post-formed gridshells.
In International Association for Shell and Spatial Structures (IASS) Symposium. Amsterdam.

Deleuze G., 1997. Differenza e Ripetizione. Raffaello Cortina Editore, Milano.

Diodato R., 2005. Estetica del Virtuale. Bruno Mondatori, Milano.

De Luca, L., Busayarata, C., Stefania, C., Véronb, \& P., Florenzanoa, M., 2011. A semantic-based platform for the digital analysis of architectural heritage. Computer and Graphics, 35(2).

Garagnani, S., 2012. Building Information Modeling semantico e rilievi ad alta risoluzione di siti appartenenti al Patrimonio Culturale (Semantic Building Information Modeling and high definition surveys for Cultural Heritage sites), DISEGNARECON, 5 (11), 297-302.

Gatys, L. A., Ecker, A. S., Bethge, M., 2015. A neural algorithm of artistic style. CoRR abs/1508.06576. https://arxiv.org/pdf/1508.06576.pdf

Levy P., 1997. Il virtuale. Raffaello Cortina Editore, Milano.

Riemer, J. J., \& Callery, B. G., 2013. Collaborative Access to Virtual Museum Collection Information: Seeing Through the Walls. Routledge, London.

Repola, L., 2008. Architettura e Variazione attraverso Gilles Deleuze. Istituto Italiano per gli Studi Filosofici, Napoli.

Repola, L., 2016. 3D Survey for analysis and comprehension of Hitite hieroglyphic through new forms of representation. In The Reasons of the Drawing, Gangemi Editore, Roma.

Repola, L., 2017. Spazi immersivi e figurazioni virtuali. In Le stanze del tempo. La collezione d'arte di Rocco Pagliara tra passato e futuro, Università Suor Orsola Benincasa, Napoli.

Schachner, A., 2011. Hattuscha. Auf der Suche nach dem sagenhaften Großreich der Hethiter. C. H. Beck Verlag, München.

Schachner, A. Bolatti Guzzo, N., Kühn, S., Marazzi, M., Repola, L., 2016. Die Ausgrabungen in Boğazköy-Hattuša 2015. Archäologischer Anzeiger, AA 2016/1, pp. 24-42.

Seeher J., 2011. Gods Carved in Stone. The Hittite Rock Sanctuary of Yazılıkaya. Ege Yayınları, Istanbul.

Ugo V., 2008. MÍMĒSIS - Sulla critica della rappresentazione nell'architettura. Maggioli Editore. Rimini.

Unali M., 2008. Abitare Virtuale significa rappresentare. Edizioni Kappa, Roma. 